\title{
Intensity discrimination of tone bursts and the form of the Weber function*
}

\author{
PAUL N. SCHACKNOW and DAVID H. RAAB \\ Brooklyn College of the City University of New York, Brooklyn, New York 11210
}

\begin{abstract}
Intensity discrimination functions were determined for tone bursts at four test frequencies: $250,1,000,4,000$, and $7,000 \mathrm{~Hz}$. Slopes of best-fitting lines ( $\Delta \mathrm{I}$ in dB SL vs 1 in dB SL) indicate a "near-miss" to Weber's law at all four frequencies. The use of information provided by harmonics of the stimulus is discussed; it is concluded that-at least for high-frequency tones - such cues are not the basis for the improved acuity found at higher sensation levels.
\end{abstract}

The fact that intensity discrimination for tone bursts does not follow Weber's law has been used by McGill and Goldberg $(1968 \mathrm{a}, \mathrm{b})$ to support a neural counting model of detection and discrimination (McGill, 1967). Specifically, plots of $\Delta I$ in dB SL against $I$ in dB SL (SL $=$ sensation level) were well fitted by linear functions whose slopes were approximately 0.9 . (The slopes would have equalled unity had Weber's law obtained.) More recently, Viemeister has proposed that the " 'near-miss' to Weber's law reflects the observer's use of information at aural harmonics" of the test tones (Viemeister, 1972, p. 1265).

Since the studies cited above all used tones at or near $1,000 \mathrm{~Hz}$, the question remains of whether intensity discrimination functions at other frequencies would also show improved discrimination at higher intensity levels. Earlier studies by Harris (1963) and by Campbell (1966) used several test frequencies, but yielded discrepant results. We have computed intensity discrimination functions for the data given in Harris's Table 1. Weber fractions for levels of 20 phons and above were averaged across listeners. Slopes of the best-fitting lines were 1.01 , 0.97 , and 0.96 for test frequencies of $125,1,000$, and $6,000 \mathrm{~Hz}$, respectively. While these data would appear to support Weber's law, Campbell's results (1966, Fig. 2), with frequencies of $250,1,000$, and $4,000 \mathrm{~Hz}$, are more in accord with McGill's observations of the "near-miss" to Weber's law.

Since the existence of the "near-miss" at frequencies other than $1,000 \mathrm{~Hz}$ was in question, and since this issue bears on the choice among possible mechanisms mediating auditory intensity discrimination, we undertook to investigate tonal intensity discrimination at four frequencies between 250 and $7,000 \mathrm{~Hz}$.

\section{PROCEDURES}

Intensity difference limens were determined for two Ss, using a two-interval, forced-choice variation of the blocked-trials staircase method. The Ss were young adults, one male and one

*This research was supported by a grant (GB 12841X1) from the National Science Foundation and by funds provided by Brooklyn College. We are very grateful to Linda Grossman, who volunteered to spend many hours serving as a $S$. female, with normal audiograms. Weber fractions, $(\Delta / / I)$ corresponding to approximately $75 \%$ correct decisions were computed for four frequencies of tone: $250,1,000,4,000$, and $7,000 \mathrm{~Hz} .1$ The stimuli were bursts of tone presented at three SLs: 30,50 , and $70 \mathrm{~dB}$. They were presented to the S's right ear through a PDR-10 earphone mounted in a MX/41-AR cushion. Each burst lasted for $250 \mathrm{msec}$ and had a nominal rise/fall time of $10 \mathrm{msec}$. The interval between the two tone bursts comprising a trial was $550 \mathrm{msec}$. Indicator lights marked the observation intervals and provided feedback.

\section{RESULTS AND DISCUSSION}

Results for the two listeners are presented in Table 1. Weber ratios are given in decibels. Regression lines $(\Delta \mathrm{I}$ in dB SL vs $I$ in $\mathrm{dB} S \mathrm{SL}$ ) were fitted to the data; slopes are given in the last column of Table 1. The data show that, for both Ss, discrimination is more acute at $70 \mathrm{~dB} \mathrm{SL}$ than at the lower levels. This is so at all four test frequencies. Furthermore, there is a suggestion in the data for the two Ss that the slopes of the regression lines for the 4,000 - and the $7,000-\mathrm{Hz}$ conditions are less than those for the two lower frequencies.

That our Ss made significant use of information at harmonics of the test tones seems unlikely. If harmonics produced by the earphone provided spurious information, this should have been most useful at $250 \mathrm{~Hz}$, where the transducer had to be driven hardest

Table 1

Weber Fractions $(\Delta I / I$ in $d B)$ and Slopes of Intensity Discrimination Functions for Tone Bursts

\begin{tabular}{|c|c|c|c|c|}
\hline \multirow{2}{*}{$\begin{array}{l}\text { Stimulus Fre- } \\
\text { quency }(\mathrm{Hz})\end{array}$} & \multicolumn{3}{|c|}{ Sensation Levels } & \multirow[b]{2}{*}{ Slopes } \\
\hline & $30 \mathrm{~dB}$ & $50 \mathrm{~dB}$ & $70 \mathrm{~dB}$ & \\
\hline 250 & $\begin{array}{l}-4.5 \\
-4.2\end{array}$ & $\begin{array}{l}-7.1 \\
-4.5\end{array}$ & $\begin{array}{l}-9.1 \\
-7.8\end{array}$ & $\begin{array}{l}0.89 \\
0.91\end{array}$ \\
\hline 1000 & $\begin{array}{l}-4.9 \\
-5.5\end{array}$ & $\begin{array}{l}-6.1 \\
-5.2\end{array}$ & $\begin{array}{r}-10.3 \\
-8.8\end{array}$ & $\begin{array}{l}0.87 \\
0.92\end{array}$ \\
\hline 4000 & $\begin{array}{l}-5.6 \\
-1.5\end{array}$ & $\begin{array}{l}-6.3 \\
-1.5\end{array}$ & $\begin{array}{r}-11.0 \\
-6.9\end{array}$ & $\begin{array}{l}0.87 \\
0.87\end{array}$ \\
\hline 7000 & $\begin{array}{l}-4.0 \\
-3.0\end{array}$ & $\begin{array}{l}-5.0 \\
-2.3\end{array}$ & $\begin{array}{r}-11.6 \\
-7.8\end{array}$ & $\begin{array}{l}0.81 \\
0.88\end{array}$ \\
\hline
\end{tabular}

Note-For each condition, the upper value refers to $\delta S 1$ and the lower value to $\delta S 2$. 
to produce the three sensation levels. For example, input signals producing equal sensation levels at 250 and $1,000 \mathrm{~Hz}$ differed by $16 \mathrm{~dB}$ for $\mathrm{S} 1$ and by $22 \mathrm{~dB}$ for S 2.2 Even if the tones at 250 and $7,000 \mathrm{~Hz}$ were equally impure, harmonics within the auditory spectrum are more numerous and more audible in the case of the lower frequency.

A similar argument can probably be made with respect to subjective harmonics. If the "near-miss" is somehow a function of aural harmonics, one would expect this departure from Weber's law to be greatest at $250 \mathrm{~Hz}$ and virtually absent at $7,000 \mathrm{~Hz}$. Since this is not the case, we conclude-at least with respect to high-frequency tones-that the "near-miss" to Weber's law can occur in the absence of harmonic distortion.

If harmonics of the stimulus (equipment-produced or aural) are not used by the listener, two other kinds of "off-frequency" information may provide the basis for the better discrimination found at higher levels. These are: listening for "energy-splatter" (Leshowitz \& Wightman, 1971), and listening at the edges of "excitation patterns" (Siebert, 1968; Zwicker, 1970). Both mechanisms, as well as neural counting models, remain among the more plausible explanations of the "near-miss" to Weber's law.

\section{REFERENCES}

Campbell, R. A. Auditory intensity perception and neural coding. Journal of the Acoustical Society of America, 1966, $39,1030-1033$.

Harris, J. D. Loudness discrimination. Journal of Speech \& Hearing Disorders, Monograph Supplement No. 11, 1963, 1-63.

Leshowitz, B., \& Wightman, F. L. On-frequency masking with continuous sinusoids. Journal of the Acoustical Society of America, 1971, 49, 1180-1190.

MCGill, W. J. Neural counting mechanisms and energy detection in audition. Journal of Mathematical Psychology, 1967, 4, 351-376.
McGill, W. J., \& Goldberg, J. P. A study of the near-miss involving Weber's law and pure-tone intensity discrimination. Perception \& Psychophysics, 1968a, 4, 105-109.

McGill, W. J., \& Goldberg, J. P. Pure-tone intensity discrimination and energy detection. Journal of the Acoustical Society of America, $1968 \mathrm{~b}, 44,576-581$.

Siebert, W. M. Stimulus transformations in the peripheral auditory system. In $P$. Kolers and $M$. Eden (Eds.), Recognizing patterns. Cambridge: M.I.T. Press, 1968. Chap. 4.

Viemeister, N. F. Intensity discrimination of pulsed sinusoids: The effects of filtered noise. Journal of the A coustical Society of America, 1972, 51, 1265-1269.

Zwicker, E. Masking and psychological excitation as consequences of the ear's frequency analysis. In R. Plomp and G. F. Smoorenburg (Eds.), Frequency analysis and periodicity detection in hearing. Leiden: Sijthoff, 1970. Pp. 376-396.

\section{NOTES}

1. For a standard intensity, $I$, the difference limen, $\Delta I$, is defined as follows:

$$
\Delta \mathrm{I}=\mathrm{I} \mathbf{7 5} \%-\mathrm{I},
$$

where $\mathbf{I}_{\mathbf{7 5} \%}$ is the intensity of the stimulus that is "just noticeably louder" than I. Since $\Delta I, \mathbf{l}_{75 \%}$, and I are all intensities, they can be referred to each other or to some other intensity, e.g., the listener's absolute threshold.

2. System distortion was measured at the output of the earphone as follows: Sound pressures generated in a $6-\mathrm{cm}^{3}$ coupler (ANSI Type 1) were transduced by a condenser microphone (W.E. 640-AA), whose output was amplified and fed to a wave analyzer (G.R. Type 736-A). At $70 \mathrm{~dB}$ SPL, the second harmonic (the principal distortion component) was approximately $-60 \mathrm{~dB}$ re the fundamental at each test frequency. Increasing tonal intensity to $90 \mathrm{~dB}$ SPL increased the relative level of the second harmonic by $3-4 \mathrm{~dB}$. At $70 \mathrm{~dB}$ SL, therefore, there was slightly more distortion at $250 \mathrm{~Hz}$ than at the higher frequencies.

(Received for publication May 21, 1973; revision received June 19,1973 .) 